\title{
Comparing durability of Steel Reinforced Grout (SRG) and Textile Reinforced Concrete (TRC) for structural retrofitting
}

\author{
Cesare Signorini · Andrea Nobili
}

Received: date / Accepted: date

\begin{abstract}
We assess the tensile performance of Steel Reinforced Grout (SRG) and of Fabric Reinforced Cementitious Matrix/Textile Reinforced Concrete (FRCM / TRC), upon exposure to aggressive environments. Galvanized and brass-plated Ultra High Tensile Strength Steel (UHTSS) fabrics are considered for SRG, while carbon, AR-glass, basalt and PBO fabrics are investigated for TRC, in a common cement mortar. Exposure to the aggressive environments is realized by specimen immersion for 1000 hours (41.6 days) at controlled temperature in distilled water as well as alkaline, saline and acid solutions. Mechanical performance of rectangular 1-ply coupons is assessed in uni-axial traction: Ultimate strength and elongation, dissipated energy at failure and environmental conversion factors for design values are calculated and compared. It is found that significant performance difference exists in dependence of the aggressive environment under consideration. As a result, careful selection of the reinforcing fabric leads to substantial advantage in terms of durability, that should be capitalized upon at the design stage. A simple material selection matrix is presented which suggests the best reinforcing textile/aggressive environment combination for design purposes.
\end{abstract}

Keywords TRC $\cdot \mathrm{SRG} \cdot$ durability $\cdot$ environmental conversion factors

\section{Introduction}

Inorganic matrix composite materials, such as Fabric Reinforced Cementitious Matrix (FRCM) or Textile Reinforced Concrete/Mortar (TRC/TRM), are a new class of composite systems that is gaining grounds for structural rehabilitation and retrofitting $[9,20,3]$. Over the wide class of organic matrix composites, among which we mention

C. Signorini

Centro Interdipartimentale En\&Tech, Tecnopolo, p.le Europa, 1, 42124 Reggio Emilia, Italy Tel.: +390522523540

E-mail: cesare.signorini@unimore.it

A. Nobili

Dipartimento di Ingegneria Enzo Ferrari, via Vivarelli 10, 41125 Modena, Italy 
the established group of Fabric Reinforced Polymers (FRP), FRCM/TRC offer several important advantages, such as affinity with traditional building materials (fire clay, cement, masonry) and reversibility of the intervention (which are crucial assets when dealing with cultural heritage retrofitting [27]), resistance to high temperature [22] and UV exposure, applicability in the presence of water and on wet substrates $[2, \S 3.1]$. When High Tensile Strength Steel (HTSS) is used as the reinforcing fabric, the composite goes under the name of S-FRCM or Steel Reinforced Grout (SRG) [18, 6]. After two decades of extensive research, the role of FRCM/TRC as strengthening systems is currently shifting from $R \& D$ to the application stage. This evolution is supported by the appearance of new code guidelines, such as the recently approved Italian specifications [11] and acceptance criteria [12], which follow upon the already established [1] and [2]. One important issue, that is discussed in these guidelines, concerns the performance decay associated to exposure to aggressive environments. In fact, following [24], "a major challenge is in incorporating durability test methods into a standard acceptance test protocol". Although ACI and Italian guidelines agree on the conditioning regimes to be considered for durability assessment (see [16]), they take a different stance on how to move from test data to design values. Beside experimentation, ACI does not provide specific prescriptions for taking into account performance reduction as a result of aggressive environment exposure. In contrast, the Italian regulation introduces a environmental conversion factor $\eta_{a}$ for reducing design values $[11, \S 3.2]$, in analogy with the approach already proposed for FRP [10, $\S 3.5 .1]$. In fact, in the lack of specific tests, it provides the one-fits-them-all coefficient $\eta_{a}=70 \%$, common to all aggressive environments. Interestingly, this is precisely the factor attached to exposure to aggressive environments of aramid/epoxy FRP and should be confronted with $\eta_{a}=85 \%$ assumed for carbon/epoxy FRP [10, Table 3-2]. Consequently, according to the Italian regulation, FRCM / TRC are no better performing than FRPs in aggressive environments in general. This is particularly remarkable if one considers that "better long-term durability" is credited among the major assets of FRCM/TRC systems [25]. In this work, we show that this stance is not always justified in terms of design values. Only a small number of papers have appeared in the literature discussing the performance decay of FRCM/TRC systems associated to exposure to aggressive environments and to humidity and gas penetration in the reinforcing system. Indeed, according to the recent review by [20], "Future work in this field should be directed at [..] understanding the durability of the strengthening system". Furthermore, opposing results are sometimes encountered. In her interesting dissertation, [4] investigates the tensile strength of PBO and carbon FRCM 1-ply coupons after immersion in alkaline and saline solutions, and after exposure to water vapour and freeze-thaw cycles. Unexpectedly, performance appears consistently unaffected by exposure, if not enhanced. In fact, [5] write "Results indicate there are no significant degradation concerns for the environments cited. On the contrary, strength improvements are noted on most exposures probably due to continued hydration after 28 days". [26] considers tensile performance of AR-glass FRCM coupons after immersion in a saline or alkaline solution. Consideration of the effect on the isolated components, namely dry fabric and lime mortar, shows that exposure little affects AR-glass. Indeed, this result parallels the findings of [30] and [29], for glass reinforced cement (GRC), of [15] and [23] for dry fabric in alkaline environment. In fact, exposure mainly impairs the lime mortar and this, in turn, promotes delamination failure and large data scattering. Exposed specimens present a residual strength that is roughly $75 \%$ of that pertaining to the control group, in the 
mean. Although this appears in line with the conversion factor given by the Italian regulation, consideration of design values offers a different perspective. In the paper by [32], a detailed investigation is presented for carbon FRCM that considers the role of curing time of the lime mortar as well as the impact of exposure on design values. For these, reductions in excess of $60 \%$ of the control group are easily encountered (residual strength $<40 \%$ ), although long curing time effectively mitigates the decay. A careful study is performed to correlate the crack pattern evolution against the performance decay. It is found that the average crack spacing provides a reliable measure of matrix/fabric bond degradation at all test stages, as pointed out also by [35], using the technique of Digital Image Correlation (DIC) too. Recently, [16] presented a durability analysis of AR-glass FRCM after immersion for 1000 hours in a saline solution or in water at $60{ }^{\circ} \mathrm{C}$. Single shear-bond tests show that adhesion to a fire clay support is reduced by more than $20 \%$ (surprisingly, relative data scattering is decreased in the exposed groups) and the hydraulic mortar is little affected by exposure. In contrast to the findings of [28], dry glass fabric performance is reduced by more than $30 \%$ in the mean. A likely explanation of this result may be traced to the exposure temperature, that is sensibly higher than that suggested by the guidelines (namely $23^{\circ} \mathrm{C}$ ). In fact, [23] point out that "a maximum temperature should be individuated in conditioning protocols, otherwise unreal detrimental effects could be produced". In their work, they assess the tensile strength of E- and AR-glass, carbon, basalt, PBO and steel strands extracted from dry fabrics after exposure to different alkaline environments at various temperatures, the latter designed as to simulate different service life spans. They find that "E-glass fibres and basalt fibres confirmed to be highly sensitive to the alkaline environments", while "carbon and steel fibres did not exhibit a chemical vulnerability". The protective role of a polymeric coating is also investigated. [14] consider immersion for 15, 30 and 41.6 days of dry steel textiles in Substitute Ocean Water (SOW), presumably at laboratory temperature. They report that exposure produces negligible effect on the stress-strain curves and therefore propose $\eta_{a}=95.5 \%$ for the longest immersion. From this literature review, it clearly appears that durability is a complex function of fabric coating, matrix composition and curing time. We also observe that, to the best of our knowledge, no all-around durability investigation is available concerning SRG. In this paper, we investigate durability of FRCM/TRC systems reinforced with different fabrics, including HTSS, embedded in a common cement mortar. Focus is set on the determination of environmental conversion factors for design purposes, which provide easy and accessible guidance to the best choice of the reinforcing fabric in dependence of the aggressive environment to be faced.

\section{Materials and methods}

\subsection{Materials}

Four typical reinforcing textiles, namely carbon, Alkali-Resistant (AR) glass, basalt and poliparafenilenbenzobisoxazolo (PBO), are assessed within the TRC class, see Fig.1(a-d). Similarly, two Ultra-High Strength Steel (UHSS) fabrics are employed for SRG, namely zinc-plated and brass-plated, which differ by the surface treatment that is applied to prevent chemical corrosion, see Fig.1(e-f). The main geometrical and mechanical properties of the fabrics are reported in Tab.1 for both TRC and SRG 


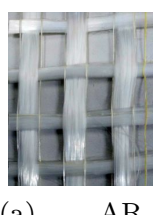

(a) glass

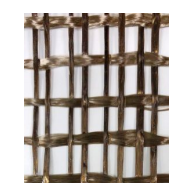

(b) Basalt (pre-preg warp yarns

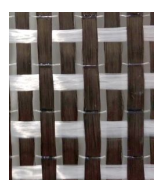

(c) Carbon (with AR-

glass

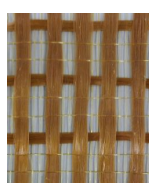

(d) $\mathrm{PBO}$

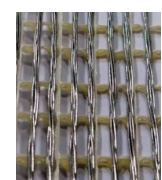

(e) Zinc- (f) Brassplated UHTS steel UHTS steel

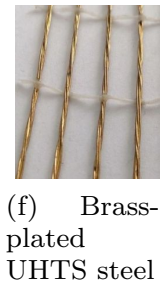

Fig. 1 Reinforcing textiles for TRC and SRG specimens

Table 1 Mechanical and physical properties of the reinforcing fabrics for TRC and SRG specimens

\begin{tabular}{l|cccc|cc}
\hline \multirow{2}{*}{ Characteristic [Unit] } & \multicolumn{3}{|c|}{ Fabric (TRC) } & \multicolumn{2}{c}{ Fabric (SRG) } \\
& G & B & C & P & ZS & BS \\
\hline Fibre/wire char. strength, $f_{k}[\mathrm{GPa}]$ & 1.4 & 2.9 & 5.1 & 5.8 & 2.9 & 3.1 \\
Fibre/wire char. strain, $\varepsilon_{k}[\mathrm{mstrain}]$ & 20 & 31 & 21 & 25 & 15 & 22 \\
Fibre/wire elastic modulus, $E_{f}[\mathrm{GPa}]$ & 74 & 86 & 245 & 270 & 205 & 205 \\
Fibre/wire density [g/cm $\left.{ }^{3}\right]$ & 2.5 & 2.7 & 1.8 & 1.6 & 7.9 & 7.9 \\
\hline Fabric specific weight $\left[\mathrm{g} / \mathrm{cm}^{2}\right]$ & 300 & 300 & 160 & 110 & 670 & 765 \\
Grid spacing [mm] & 12 & 8 & 5 & 10 & 6 & 6 \\
Equivalent thickness, $t_{f}[\mathrm{~mm}]$ & 0.07 & 0.11 & 0.09 & 0.05 & 0.10 & 0.08 \\
\hline
\end{tabular}

Table 2 Mechanical and physical properties of the cement mortar

\begin{tabular}{lcc}
\hline Characteristic [Regulation] & Unit & Value \\
\hline Max. grain size & $\mu \mathrm{m}$ & 500 \\
Permeability to water [EN 1504-2] & $\mathrm{m}$ & 0.94 \\
Water absorption [EN 1062-3] & $\mathrm{kg} / \mathrm{m}^{2} \mathrm{~h}^{-0.5}$ & 0.08 \\
Flexural strength [EN 196-1] & $\mathrm{MPa}$ & 4.0 \\
Compressive strength [EN 12190] & $\mathrm{MPa}$ & 27.0 \\
Elastic modulus [EN 13412] & $\mathrm{GPa}$ & 15.2 \\
Adhesion to concrete [EN 1542] & $\mathrm{MPa}$ & 1.1 \\
\hline
\end{tabular}

reinforcing techniques. The corresponding mechanical properties for SRG are well in line with the ranges discussed in [14] for the steel cord tensile strength and elastic modulus and for the fabric density and maximum load. A commercially available cement mortar with structural capability (Monotop X2, Sika Spa) is adopted as the embedding matrix, common to all specimens. Mortar properties, as given by the manufacturer, are reported in Table 2 together with flexural performance data. These are assessed, as detailed in Sec.3.1, through three-point bending (3PB) tests.

\subsection{Specimen manufacturing}

Six $\left(b \times h \times L_{f}\right)=40 \times 40 \times 160 \mathrm{~cm}$ prismatic specimens for mortar characterization are manufactured, according to [36], in a standard rectified steel formwork and then vibro-compacted. Specimens undergo moist-curing in a polypropylene bag for 7 days and then curing at $20^{\circ} \mathrm{C}$ and $65 \%$ relative humidity $(\mathrm{RH})$ for further 21 days in a climatic chamber (HPP110, Memmert GmbH + Co. KG). 
Table 3 Geometrical data of specimens for tensile testing

\begin{tabular}{lcccc}
\hline Fabric & $\begin{array}{c}\text { Grid spacing } \\
\text { (warp) }[\mathrm{mm}]\end{array}$ & $\begin{array}{c}w_{d} \\
{[\mathrm{~mm}]}\end{array}$ & $\begin{array}{c}\text { Strands } \\
{[-]}\end{array}$ & $\begin{array}{c}A_{f} \\
{\left[\mathrm{~mm}^{2}\right]}\end{array}$ \\
\hline $\mathrm{C}$ & 5 & 35 & 7 & 3.10 \\
$\mathrm{P}$ & 10 & 30 & 3 & 1.37 \\
$\mathrm{G}$ & 12 & 36 & 3 & 2.16 \\
$\mathrm{~B}$ & 8 & 32 & 4 & 3.58 \\
$\mathrm{ZS}$ & 6 & 36 & 6 & 3.23 \\
$\mathrm{BS}$ & 6 & 36 & 6 & 3.23 \\
\hline
\end{tabular}

Specimens for tensile testing consist of 1-ply rectangular coupons, manufactured on a one-by-one basis in a suitably designed polyethylene formwork. Coupon geometry is shown in Fig.2(c). The gauge length is $L_{g}=250 \mathrm{~mm}$. The specimen width, $w_{d}$, is reported in Tab.3 and it varies across different reinforcing fabrics. Indeed, it is designed so as to accommodate an integer number of yarns (i.e. it is a multiple of the mesh spacing) in the warp direction.

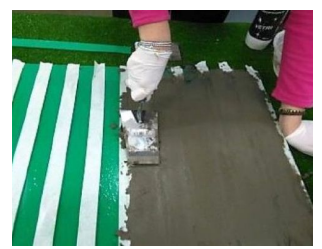

(a)

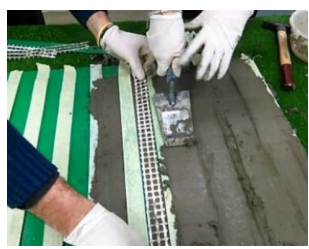

(b)

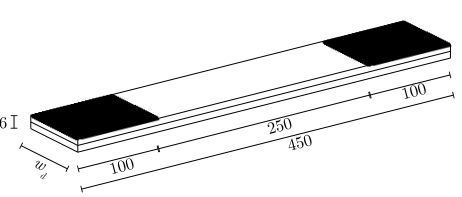

(c)

Fig. 2 TRC specimen manufacturing and geometry: (a) formwork with equidistant spacers and mortar laying, (b) fabric placing and (c) final dimensions [in $\mathrm{mm}$ ] of the coupons, whose width $w_{d}$ is an integer multiple of the fabric grid spacing (see Table 3 ).

The manufacturing protocol follows closely the procedure already described in $[26,28,34,21,33]$ and hereinafter summarized. A first layer of cement mortar is applied on the lubricated formwork in between pairs of 3-mm-thick spacers, Fig.2(a). These spacers confine the mortar around and provide reference for scraping the excess of material on top. Successively, the reinforcing fabric is gently pressed onto the fresh cement, Fig.2(b). A second layer of spacers is placed on top of the first to provide reference for the next mortar layer and to constrain the fabric in place. This procedure ensures standardized fabric placing at the coupon mid-plane and avoids cutting from a larger sheet. This is especially important in consideration of the role that cutting-induced-cracks play in conveying the aggressive agent inside the specimen. Following the guidelines [1], 7-day moist-curing in the formwork is followed by stripping and then by 21-day curing at laboratory conditions. 100-mm long AR-glass tabs are epoxy-glued at the specimen ends to accommodate for the clamping grips at the testing stage. 
Table 4 Aggressive environments under testing. Room temperature is $21 \pm 2^{\circ} \mathrm{C}(70 \pm 3.6 \mathrm{~F})$

\begin{tabular}{lcccc}
\hline Environment & $\begin{array}{c}\text { Curing } \\
\text { [days] }\end{array}$ & $\begin{array}{c}\text { Time } \\
\text { of exposure }\end{array}$ & $\begin{array}{c}\text { Temp. } \\
{ }^{\circ} \mathrm{C}\end{array}$ & Ref. \\
\hline CC & 28 & - & room & - \\
SW & 28 & 1000 hrs & $23 \pm 1$ & {$[1$, Table 2], [12] } \\
AK & 28 & $1000 \mathrm{hrs}$ & $23 \pm 1$ & {$[1$, Table 2], [12] } \\
HA & 28 & $1000 \mathrm{hrs}$ & room & {$[19,28]$} \\
DW & 28 & $1000 \mathrm{hrs}$ & room & {$[8,28]$} \\
\hline
\end{tabular}

\subsection{Aggressive environments}

Specimens are immersed for 1000 hours (41.6 days) at constant temperature in the aggressive environments listed in Tab.4 along with the relevant guidelines, see also [28]. For the sake of comparison, control specimens (CC) undergo extra curing at laboratory conditions for the same amount of time.

The alkaline environment $(\mathrm{AK})$ is a caustic soda $(\mathrm{NaOH})$ aqueous solution with $\mathrm{pH}$ 10. This solution is comparable to Environment D of [23] which, however, is $\mathrm{pH}$ 14. In fact, Environment D "may appear too severe in order to reproduce service conditions in buildings" [23]. The saline environment (SW) is a $3.5 \%$ weight sodium chloride $(\mathrm{NaCl})$ aqueous solution, which, according to [7], simulates the world's oceans average salinity (substitute ocean water, SOW). This is the artificial aging protocol considered in [14] at 15, 30 and 41 days. Following the procedure suggested by [19], immersion in a 1M hydrogen chloride acid solution (HA), pH 2.5, diluted from hydrochloric acid ( $\mathrm{HCl} 37 \%$ RPE Carlo Erba Reagents Srl), is also considered. Together, AK and HA provide double-end insight into the effects of extreme $\mathrm{pH}$ conditions. Finally, to single out the role of specimen immersion, distilled water (DW) is also investigated [1] for comparison with SW and AK. As such, this test is not fully compliant with the specifications given in [8], which demand consideration of a higher temperature (namely, $38^{\circ} \mathrm{C}$ ).

\subsection{Three-point bending tests}

Three-point bending (3PB) tests are performed on plain mortar prisms according to the guidelines UNI EN 1015-07 [36], to assess mechanical performance in flexure. Tests are carried out in a electro-mechanic Universal Testing Machine (UTM), equipped with a two-point support and a floating knife connected to a $5 \mathrm{kN}$ load cell (Instron 5567). Supports are placed $100 \mathrm{~mm}$ apart (distance $L_{s}$ ) and the floating knife moves at the nominal displacement rate of $1 \mathrm{~mm} / \mathrm{min}$ (equivalent to $50 \div 100$ $\left.\mathrm{N} \mathrm{s}^{-1}\right)$.

\subsection{Uni-axial tensile tests}

Monotonic uni-axial tensile tests are performed in the same UTM, now equipped with two self-aligning wedge grips [1]. The upper grip is connected to a $30 \mathrm{kN}$ load cell and to the moving crosshead through a double hinge. Elongation occurs at the nominal displacement rate $\dot{\delta_{n}}=0.5 \mathrm{~mm} / \mathrm{min}$, that is a little slower $(-17 \%)$ than 
the nominal rate $0.01 \mathrm{~mm} \mathrm{~s}^{-1}$ considered in [14]. This displacement rate, normalized to the gauge length, corresponds to the strain rate $\dot{\varepsilon}=2 \mathrm{mstrain} / \mathrm{min}$ and it is compliant with the RILEM guidelines [31].

\subsection{Digital Image Correlation}

To monitor the actual elongation rate of the specimen during tensile testing, a stereoscopic 3 MPixel Digital Imaging Correlation (DIC) system is employed (Q-400, Dantec Dynamics A/S, Denmark). The displacement field on the speckled surface of the specimen is acquired at a $5 \mathrm{~Hz}$ sampling rate.

As observed by Nobili [26], the correction strongly affects the evaluation of the ultimate tensile elongation (UTE) as well as of the cracked modulus.

The actual displacement rate considered for the computation is given in Eqn.(1). It is obtained by linearly fitting the measured displacement of a point close to the upper wedge clamp. The comparison between the nominal and the actual displacement rates for a typical specimen is available as supplementary material.

$$
\dot{\delta}_{\text {meas }}=0.471 \mathrm{~mm} \mathrm{~min}^{-1}
$$

\section{Results}

\subsection{Mortar characterization}

The average stress-strain curve in flexure, taken over six mortar prisms, together with \pm 1 standard deviation bands is available as supplementary material.

Data scattering is remarkably narrow. As in standard practice, the stress $\sigma$ and the strain $\varepsilon$ are obtained, respectively, from the load, $P$, applied at the floating anvil and from the mid-span displacement, $\delta$, according to the classical strength of material relations

$$
\sigma=\frac{3}{2} \frac{L_{s}}{b h^{2}} P, \quad \varepsilon=\frac{6 h}{L_{s}^{2}} \delta
$$

The mean secant elastic modulus in flexure, $E_{f}$, is evaluated as the mean slope of the secant lines going through two reference points in each strength curve [4, Eq.(3) p.51].

$$
\mu\left(E_{f}\right)=\frac{\sigma_{@ 90 \% \mathrm{UFS}}-\sigma_{@ 60 \% \mathrm{UFS}}}{\varepsilon_{@ 90 \% \mathrm{UFS}}-\varepsilon_{@ 60 \% \mathrm{UFS}}} .
$$

being UFS the ultimate flexural strength of the mortar. For the mortar under investigation we have

$$
\mu\left(E_{f}\right)=(629 \pm 5) \mathrm{MPa}, \quad \text { and } \quad \mu(\mathrm{UFS})=(2.9 \pm 0.3) \mathrm{MPa},
$$

respectively for the mean secant modulus and for the mean ultimate flexural strength. 


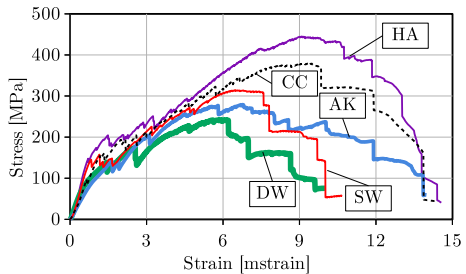

(a) Carbon (C)

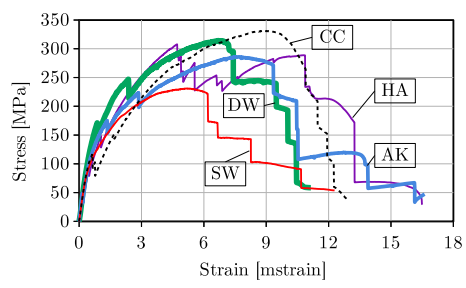

(c) AR-glass (G)

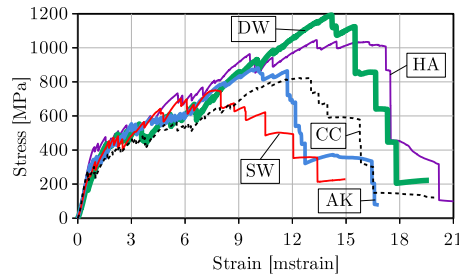

(b) PBO (P)

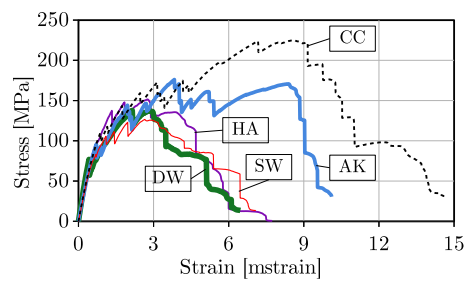

(d) Basalt (B)

Fig. 3 Mean stress-strain curves of TRC specimens in the tested environments: CC, control, (black, dotted); DW, distilled water, (green, thick solid); HA, hydrochloric acid, (violet, thin solid); AK, alkaline solution, (light-blue, solid) and SW, salt-water, (red, solid)

\subsection{Monotonic tensile tests}

\subsubsection{Multifilament TRC}

Fig.3 compares the mean strength curves, for each TRC specimen group, across all tested environments. Mean curves are obtained by averaging over six specimens within a group. As detailed in $[12, \S 2.1 .1]$, stress is conventionally scaled over the dry reinforcement cross-sectional area, $A_{f}$, reported in Table 3 . Given the wide range of ultimate tensile strength (UTS) levels that are attained by different reinforcements (e.g. PBO provides more than twice the strength of carbon in the control group and twice the ductility in the distilled water group), the same axis scale could not be adopted for all groups.

For better comparison, Figs.4 presents a bar-chart illustration of UTS for the reinforcing textiles across all environments. The same confrontation, both in terms of ultimate tensile elongation (UTE) and of dissipated energy $(W)$, is provided for the sake of completeness in the supplementary material. Quantitative assessment is presented in Table 5. The following observations can be made:

- Performance of basalt reinforced TRC is strongly impaired by all aggressive environments: in fact, basalt fails the acceptance condition, put forward in [12], demanding that UTS after exposure rests above $85 \%$ of the control group performance. In the AK solution, the outcome is compatible with the findings reported in $[23$, Tab.7] for dry yarns. Performance loss in terms of UTE and energy dissipation capability is remarkable.

- AR-glass is really sensitive to SW exposure only, where the composite fails acceptance and ductility is almost halved. Other aggressive environments produce little effect, see also [26]. Energy dissipation and UTE capability behave simi- 


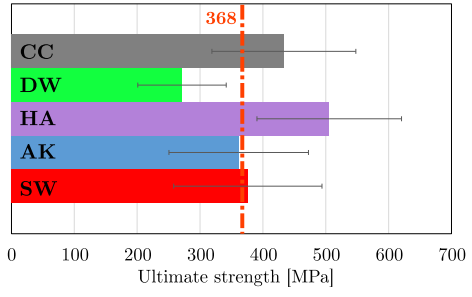

(a) Carbon (C)

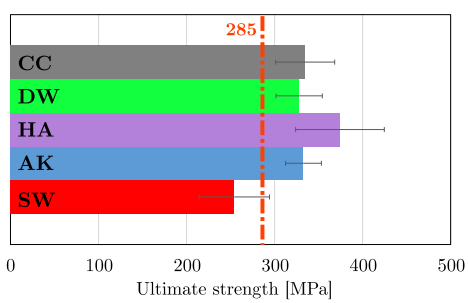

(c) AR-glass (G)

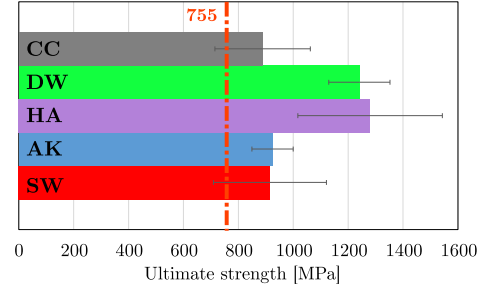

(b) $\operatorname{PBO}(\mathrm{P})$

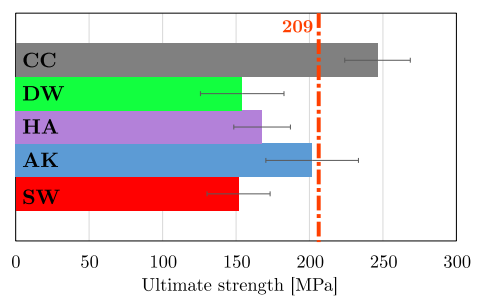

(d) Basalt (B)

Fig. 4 Ultimate tensile strength (UTS) and \pm 1 standard deviation bars for TRC specimens in all aggressive environments (CC, control, grey; DW, distilled water, green; HA, hydrochloric acid, violet; AK, alkaline solution, light-blue and SW, salt-water, red). The acceptance limit is also shown (red, dash-dot)

larly: they are unaltered in AK and HA, suffer a mild loss in DW and strongly decay in SW.

- PBO is exceptionally well performing in all aggressive environments and never fails acceptance. Indeed, this behaviour is compatible with the findings presented in [4, Fig.65]. Interestingly, UTS benefits from exposure to DW and HA and this pattern carries over to energy dissipation. Excellent performance extends to UTE, although AK and SW exposure reduce ductility by $16 \%$ and $26 \%$, respectively; yet such losses are compensated by strength gains and therefore energy dissipation remains as in the control group.

- Carbon performs surprisingly poorly when immersed in DW, where it fails acceptance, and this outcome contrasts with the results presented in [4, Fig.65]. Interestingly, carbon marginally benefits from HA exposure and this progress carries over to energy dissipation. In SW and AK solutions, it suffers a mild performance loss and stands on the boundary of acceptance. It is worth observing that [23] find zero tensile strength loss for carbon under under any (alkaline) aggressive environment for all exposure times.

- Data scattering is generally acceptable and comparable with the uncertainty usually encountered in durability tests, which fact suggests good reproducibility of the results.

\subsection{2 $S R G$}

Fig.5 illustrates the mean stress-strain curves for zinc-plated (ZS) and brass-plated (BS) SRG coupons, with the same scaling for both axes. As expected, strength curves 
Table 5 Mean UTS, UTE and $W \mu(\cdot)$, and coefficient of variation, CoV, for all exposed TRC groups, alongside the percent variance $\Delta(\cdot)$ with respect to the control group ( $\mathrm{F}=$ fabric)

\begin{tabular}{|c|c|c|c|c|c|c|c|c|c|c|c|c|c|c|}
\hline \multirow[b]{2}{*}{$\mathbf{F}$} & \multicolumn{2}{|c|}{$\mathrm{CC}$} & \multicolumn{3}{|c|}{ SW } & \multicolumn{3}{|c|}{ AK } & \multicolumn{3}{|c|}{ DW } & \multicolumn{3}{|c|}{ HA } \\
\hline & $\begin{array}{l}\mu(f) \\
{[\mathrm{MPa}]}\end{array}$ & $\begin{array}{r}\mathrm{CoV} \\
{[\%]}\end{array}$ & $\begin{array}{l}\mu(f) \\
{[\mathrm{MPa}]}\end{array}$ & $\begin{array}{r}\mathrm{CoV} \\
{[\%]}\end{array}$ & $\begin{array}{r}\Delta f \\
{[\%]}\end{array}$ & $\begin{array}{l}\mu(f) \\
{[\mathrm{MPa}]}\end{array}$ & $\begin{array}{r}\mathrm{CoV} \\
{[\%]}\end{array}$ & $\begin{array}{r}\Delta f \\
{[\%]}\end{array}$ & $\begin{array}{l}\mu(f) \\
{[\mathrm{MPa}]}\end{array}$ & $\begin{array}{r}\mathrm{CoV} \\
{[\%]}\end{array}$ & $\begin{array}{c}\Delta f \\
{[\%]}\end{array}$ & $\begin{array}{l}\mu(f) \\
{[\mathrm{MPa}]}\end{array}$ & $\begin{array}{r}\mathrm{CoV} \\
{[\%]}\end{array}$ & $\begin{array}{r}\Delta f \\
{[\%]}\end{array}$ \\
\hline $\mathrm{C}$ & 433 & 26.4 & 376 & 31.4 & -13.2 & 362 & 30.7 & -16.6 & 271 & 25.9 & -37.4 & 505 & 22.7 & 16.6 \\
\hline $\mathrm{P}$ & 888 & 19.6 & 915 & 22.4 & 3.0 & 925 & 8.1 & 4.1 & 1240 & 9.0 & 39.7 & 1280 & 20.6 & 44.1 \\
\hline $\mathrm{G}$ & 335 & 10.0 & 254 & 15.7 & -24.0 & 333 & 6.1 & -0.6 & 328 & 8.0 & -2.1 & 374 & 13.5 & 11.8 \\
\hline B & 246 & 9.1 & 152 & 14.1 & -38.4 & 202 & 15.6 & -18.1 & 154 & 18.4 & -37.4 & 168 & 11.5 & -31.9 \\
\hline $\mathbf{F}$ & $\begin{array}{r}\mu(\varepsilon) \\
{\left[\cdot 10^{-3}\right]}\end{array}$ & $\begin{array}{r}\mathrm{CoV} \\
{[\%]}\end{array}$ & $\begin{array}{r}\mu(\varepsilon) \\
{\left[\cdot 10^{-3}\right]}\end{array}$ & $\begin{array}{r}\mathrm{CoV} \\
{[\%]}\end{array}$ & $\begin{array}{l}\Delta \varepsilon \\
{[\%]}\end{array}$ & $\begin{array}{r}\mu(\varepsilon) \\
{\left[\cdot 10^{-3}\right]}\end{array}$ & $\begin{array}{r}\mathrm{CoV} \\
{[\%]}\end{array}$ & $\begin{array}{l}\Delta \varepsilon \\
{[\%]}\end{array}$ & $\begin{array}{r}\mu(\varepsilon) \\
{\left[\cdot 10^{-3}\right]}\end{array}$ & $\begin{array}{r}\mathrm{CoV} \\
{[\%]}\end{array}$ & $\begin{array}{l}\Delta \varepsilon \\
{[\%]}\end{array}$ & $\begin{array}{r}\mu(\varepsilon) \\
{\left[\cdot 10^{-3}\right]}\end{array}$ & $\begin{array}{r}\mathrm{CoV} \\
{[\%]}\end{array}$ & $\begin{array}{l}\Delta \varepsilon \\
{[\%]}\end{array}$ \\
\hline $\mathrm{C}$ & 10.6 & 23.2 & 9.0 & 50.8 & -14.7 & 11.6 & 58.2 & 9.2 & 7.9 & 36.7 & -25.8 & 11.1 & 18.0 & 4.2 \\
\hline $\mathrm{P}$ & 14.6 & 13.3 & 11.2 & 49.2 & -19.8 & 10.7 & 14.4 & -23.5 & 16.4 & 7.9 & 17.4 & 16.1 & 21.7 & 14.8 \\
\hline $\mathrm{G}$ & 10.1 & 8.9 & 6.7 & 44.4 & -33.6 & 11.0 & 39.2 & 8.7 & 8.7 & 20.3 & -14.4 & 10.9 & 33.2 & 8.2 \\
\hline B & 10.4 & 19.0 & 3.8 & 54.6 & -64.0 & 7.4 & 32.3 & -28.9 & 3.6 & 26.1 & -65.0 & 3.4 & 38.8 & -67.1 \\
\hline $\mathbf{F}$ & $\begin{array}{r}\mu(W) \\
{[\mathrm{J}]}\end{array}$ & $\begin{array}{r}\mathrm{CoV} \\
{[\%]}\end{array}$ & $\begin{array}{r}\mu(W) \\
{[\mathrm{J}]}\end{array}$ & $\begin{array}{r}\mathrm{CoV} \\
{[\%]}\end{array}$ & $\begin{array}{r}\Delta W \\
{[\%]}\end{array}$ & $\begin{array}{r}\mu(W) \\
{[\mathrm{J}]}\end{array}$ & $\begin{array}{r}\mathrm{CoV} \\
{[\%]}\end{array}$ & $\begin{array}{r}\Delta W \\
{[\%]}\end{array}$ & $\begin{array}{r}\mu(W) \\
{[\mathrm{J}]}\end{array}$ & $\begin{array}{r}\mathrm{CoV} \\
{[\%]}\end{array}$ & $\begin{array}{r}\Delta W \\
{[\%]}\end{array}$ & $\begin{array}{r}\mu(W) \\
{[\mathrm{J}]}\end{array}$ & $\begin{array}{r}\mathrm{CoV} \\
{[\%]}\end{array}$ & $\begin{array}{r}\Delta W \\
{[\%]}\end{array}$ \\
\hline $\mathrm{C}$ & 2505 & 33.5 & 1836 & 45.6 & -26.7 & 2281 & 52.0 & -9.0 & 1184 & 55.6 & -52.7 & 2940 & 28.2 & 17.4 \\
\hline $\mathrm{P}$ & 3404 & 28.9 & 3049 & 57.5 & -10.4 & 3233 & 19.6 & -5.3 & 4845 & 17.5 & 42.3 & 5154 & 34.3 & 51.4 \\
\hline $\mathrm{G}$ & 1924 & 11.2 & 1195 & 33.4 & -37.9 & 2011 & 23.7 & 4.6 & 1618 & 17.7 & -15.9 & 2077 & 37.3 & 8.0 \\
\hline B & 2223 & 23.1 & 685 & 33.3 & -69.2 & 1401 & 33.0 & -37.0 & 637 & 37.9 & -71.4 & 549 & 41.9 & -75.3 \\
\hline
\end{tabular}

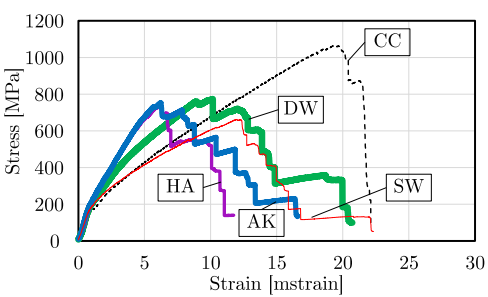

(a) Zinc-plated steel (ZS)

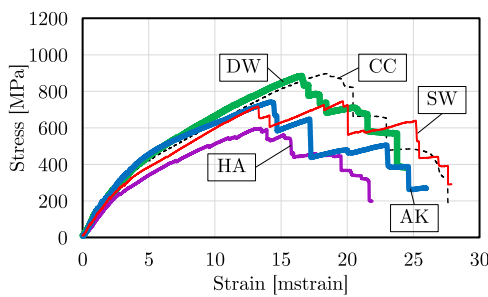

(b) Brass-plated steel (BS)

Fig. 5 Mean stress-strain curves for SRG in all tested environments: CC, control, (black, dotted); DW, distilled water, (green, thick solid); HA, hydrochloric acid, (violet, thin solid); AK, alkaline solution, (light-blue, solid) and SW, salt-water, (red, solid)

for SRG are almost perfectly bi-linear, reflecting uncracked and cracked performance, the latter extending until sudden failure occurs. This behaviour stems from the enhanced mortar-to-fabric bond formation capability of steel. Comparison of Fig.5 with [14, Fig.6] reveals a great difference in terms of UTS, while UTE is comparable. This outcome is most likely due to a different test setup and, in particular, to the confining pressure at the grips. Indeed, in our setup, the applied pressure is purposely not large enough as to prevent fabric slippage from occurring eventually inside the specimen. As a result, fabric-to-mortar adhesion determines the onset of failure prior to fabric failure. This is desirable because fabric-to-mortar adhesion is very sensitive to aggressive environment exposure and the determination of this sensitivity is precisely among the aims of our tests. Conversely, for the setup considered in [14], the stress-strain curves for the dry fabric and for the composite specimen almost coincide, i.e. fabric slippage is prevented altogether. It is therefore little surprising that negligible data scattering appears in [14, Table 4] (better than 6\% CoV for all 
groups) and that SW immersion brings little harm. This explanation is supported by similar findings presented in [13] where, in some tests, "the specimens where gripped on the dry textile out of the matrix". Of course different gripping mechanisms are possible and yet, along with [4, p.38], we observe that "gripping mechanisms that apply transversal loading (clamping) to ensure the specimen does not slip are effectively [..] producing results that are unrealistically high". Furthermore, specifically for steel cords, the Italian guidelines impose an upper limit for the UTS equal to the yield stress of the reinforcement, on the grounds that "post-elastic behaviour should be excluded for strengthening purposes" [12, §2.1.1]. We conclude that, as long as a reasonable confining pressure is consistently applied across all specimens, comparative tests are meaningful, while absolute performance remains questionable. From a durability standpoint, it appears that zinc-plated SRG is definitely more sensitive to aggressive environment exposure than brass-plated SRG, despite displaying better performance in the control group. The bar-charts of Fig. 6 for UTS, alongside the ones for UTE and $W$ available as supplementary material, combined with the corresponding Table 6 , better illustrate the point. We observe that

- brass-plated SRG behaves remarkably well in AK, SW and DW, while it greatly suffers from acid attack (HA) where it fails acceptance. Accordingly, brass-plated SRG appears an attractive candidate for seafront interventions, although large data scattering penalizes design values, see $\S 4$.

- In contrast, zinc-plated SRG behaves poorly in all environments, where it fails acceptance, with the possible exception of DW. In any environment, ductility is strongly impaired and so is energy dissipation capability.

- Data scattering is in line with TRC.

Table 6 Mean UTS, UTE and $W \mu(\cdot)$, coefficients of variance, CoV, and percent variation with respect to control group, $\Delta(\cdot)$

\begin{tabular}{|c|c|c|c|c|c|c|c|c|c|c|c|c|c|c|}
\hline $\mathbf{F}$ & $\begin{array}{c}\mathrm{C} \\
\mu(f) \\
{[\mathrm{MPa}]}\end{array}$ & $\begin{array}{r}\mathrm{CoV} \\
{[\%]}\end{array}$ & $\begin{array}{l}\mu(f) \\
{[\mathrm{MPa}]}\end{array}$ & $\begin{array}{l}\text { SW } \\
\mathrm{CoV} \\
{[\%]}\end{array}$ & $\begin{array}{r}\Delta f \\
{[\%]}\end{array}$ & $\begin{array}{l}\mu(f) \\
{[\mathrm{MPa}]}\end{array}$ & $\begin{array}{r}\mathrm{AK} \\
\mathrm{CoV} \\
{[\%]}\end{array}$ & $\begin{array}{r}\Delta f \\
{[\%]}\end{array}$ & $\begin{array}{l}\mu(f) \\
{[\mathrm{MPa}]}\end{array}$ & $\begin{array}{r}\mathrm{DW} \\
\mathrm{CoV} \\
{[\%]}\end{array}$ & $\begin{array}{r}\Delta f \\
{[\%]}\end{array}$ & $\begin{array}{l}\mu(f) \\
{[\mathrm{MPa}]}\end{array}$ & $\begin{array}{l}\mathrm{HA} \\
\mathrm{CoV} \\
{[\%]}\end{array}$ & $\begin{array}{r}\Delta f \\
{[\%]}\end{array}$ \\
\hline $\mathrm{ZS}$ & 1119 & 18.6 & 738 & 14.9 & -34.0 & 843 & 25.5 & -24.7 & 961 & 15.4 & -14.1 & 816 & 11.0 & -27.0 \\
\hline BS & 930 & 13.3 & 1088 & 16.6 & 17.0 & 1011 & 25.0 & 8.7 & 976 & 28.6 & 4.9 & 690 & 27.8 & -25.8 \\
\hline $\mathbf{F}$ & $\begin{array}{r}\mu(\varepsilon) \\
{\left[\cdot 10^{-3}\right]} \\
\end{array}$ & $\begin{array}{r}\mathrm{CoV} \\
{[\%]} \\
\end{array}$ & $\begin{array}{r}\mu(\varepsilon) \\
{\left[\cdot 10^{-3}\right]} \\
\end{array}$ & $\begin{array}{r}\mathrm{CoV} \\
{[\%]} \\
\end{array}$ & $\begin{array}{l}\Delta \varepsilon \\
{[\%]} \\
\end{array}$ & $\begin{array}{r}\mu(\varepsilon) \\
{\left[\cdot 10^{-3}\right]} \\
\end{array}$ & $\begin{array}{r}\mathrm{CoV} \\
{[\%]} \\
\end{array}$ & $\begin{array}{l}\Delta \varepsilon \\
{[\%]} \\
\end{array}$ & $\begin{array}{r}\mu(\varepsilon) \\
{\left[\cdot 10^{-3}\right]} \\
\end{array}$ & $\begin{array}{r}\mathrm{CoV} \\
{[\%]} \\
\end{array}$ & $\begin{array}{l}\Delta \varepsilon \\
{[\%]} \\
\end{array}$ & $\begin{array}{r}\mu(\varepsilon) \\
{\left[\cdot 10^{-3}\right]} \\
\end{array}$ & $\begin{array}{r}\mathrm{CoV} \\
{[\%]} \\
\end{array}$ & $\begin{array}{l}\Delta \varepsilon \\
{[\%]}\end{array}$ \\
\hline $\begin{array}{l}\mathrm{ZS} \\
\mathrm{BS}\end{array}$ & $\begin{array}{l}20.6 \\
21.1\end{array}$ & $\begin{array}{r}5.3 \\
16.7\end{array}$ & $\begin{array}{l}14.3 \\
26.5\end{array}$ & $\begin{array}{l}23.3 \\
42.1\end{array}$ & $\begin{array}{r}-30.7 \\
25.6\end{array}$ & $\begin{array}{r}9.7 \\
22.5\end{array}$ & $\begin{array}{l}41.5 \\
35.9\end{array}$ & $\begin{array}{r}-52.9 \\
6.3\end{array}$ & $\begin{array}{l}13.9 \\
19.3\end{array}$ & $\begin{array}{l}33.3 \\
16.7\end{array}$ & $\begin{array}{r}-32.7 \\
-8.5\end{array}$ & $\begin{array}{r}8.1 \\
16.1\end{array}$ & $\begin{array}{l}19.2 \\
21.6\end{array}$ & $\begin{array}{l}-60.6 \\
-23.9\end{array}$ \\
\hline $\mathbf{F}$ & $\begin{array}{r}\mu(W) \\
{[\mathrm{J}]} \\
\end{array}$ & $\begin{array}{r}\mathrm{CoV} \\
{[\%]} \\
\end{array}$ & $\begin{array}{r}\mu(W) \\
{[\mathrm{J}]} \\
\end{array}$ & $\begin{array}{r}\mathrm{CoV} \\
{[\%]} \\
\end{array}$ & $\begin{array}{r}\Delta W \\
{[\%]} \\
\end{array}$ & $\begin{array}{r}\mu(W) \\
{[\mathrm{J}]} \\
\end{array}$ & $\begin{array}{r}\mathrm{CoV} \\
{[\%]} \\
\end{array}$ & $\begin{array}{r}\Delta W \\
{[\%]} \\
\end{array}$ & $\begin{array}{r}\mu(W) \\
{[\mathrm{J}]} \\
\end{array}$ & $\begin{array}{r}\mathrm{CoV} \\
{[\%]} \\
\end{array}$ & $\begin{array}{r}\Delta W \\
{[\%]} \\
\end{array}$ & $\begin{array}{r}\mu(W) \\
{[\mathrm{J}]} \\
\end{array}$ & $\begin{array}{r}\mathrm{CoV} \\
{[\%]} \\
\end{array}$ & $\begin{array}{r}\Delta W \\
{[\%]} \\
\end{array}$ \\
\hline $\begin{array}{l}\mathrm{ZS} \\
\mathrm{BS}\end{array}$ & $\begin{array}{l}11845 \\
13805\end{array}$ & $\begin{array}{l}19.1 \\
23.6\end{array}$ & $\begin{array}{r}6317 \\
15563\end{array}$ & $\begin{array}{l}25.6 \\
41.1\end{array}$ & $\begin{array}{r}-46.7 \\
12.7\end{array}$ & $\begin{array}{r}5470 \\
13766\end{array}$ & $\begin{array}{l}45.9 \\
48.0\end{array}$ & $\begin{array}{r}-53.8 \\
-0.3\end{array}$ & $\begin{array}{r}7988 \\
12785\end{array}$ & $\begin{array}{l}37.7 \\
39.7\end{array}$ & $\begin{array}{r}-32.6 \\
-7.4\end{array}$ & $\begin{array}{l}4500 \\
7829\end{array}$ & $\begin{array}{l}38.6 \\
34.0\end{array}$ & $\begin{array}{l}-62.0 \\
-43.3\end{array}$ \\
\hline
\end{tabular}




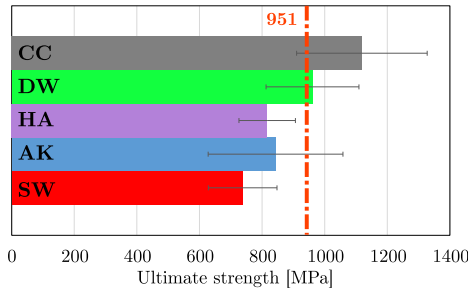

(a) Zinc-plated steel (ZS)

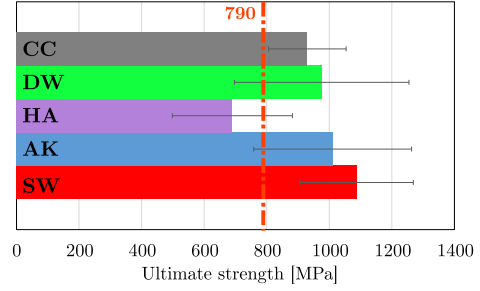

(b) Brass-plated steel (BS)

Fig. 6 Mean UTS and \pm 1 standard deviation bars for SRG (CC, control, grey; DW, distilled water, green; HA, hydrochloric acid, violet; AK, alkaline solution, light-blue and SW, saltwater, red). The acceptance limit is also shown (red, dash-dot)

\section{Environmental conversion factors and design considerations}

As discussed out in [28], data scattering plays a crucial role in the determination of design values, to the point that material $A$, that is less performing in the mean than material $\mathrm{B}$ with respect to the performance index $f$, namely $\mu\left(f_{A}\right)<\mu\left(f_{B}\right)$, may still be better performing in terms of design value,

$$
f_{d A}>f_{d_{B}}
$$

where subscript $d$ stands for design and $f_{d}$ incorporates data scattering in some form. For instance, according to the verification by the partial factor method described in $[17, \S 6.3 .3]$, we may adopt

$$
f_{d}=\frac{\eta}{\gamma_{m}} f_{k}
$$

where $f_{k}$ is the characteristic value for a normal distribution (i.e. $95 \%$ quintile), $\gamma_{m}=1 \div 1.5$ is the material partial factor and $\eta$ takes into account special conditions: In the case of environmental exposure, it is $\eta=\eta_{a}$. The Italian regulations determine design values according to Eq.(3), as in [10, Eq.(3.2)] for FRP and in [11, Eq.(3.1)] for FRCM. Alternatively, the use of the "three-sigma-rule" with no partial factor

$$
f_{d}=\mu(f)-3 \mathrm{SD}(f)
$$

is the design strategy advocated in $[1, \S 8.1]$. However, this choice puts strong emphasis on data scattering and therefore heavily favours materials which may be less performing and yet fail consistently, see [28].

The effect of exposure to the aggressive environment $a$ on the performance index $f$ may be described calculating the corresponding environmental conversion factor $\eta_{a}$

$$
\eta_{a}=f / \hat{f},
$$

which expresses the fraction of the original performance $\hat{f}$ (obtained in the control group) that remains after exposure. When multiple specimens are dealt with, we have a set of performance values after exposure, $\left\{f_{i}\right\}, i=1, \ldots, N$, to be compared with a set of control values $\left\{\hat{f}_{j}\right\}, j=1, \ldots, \hat{N}$. Then, we may treat $\eta_{a}$ as a random variable

$$
\left\{\eta_{a}\right\}_{i j}=\left\{f_{i} / \hat{f}_{j}\right\}
$$




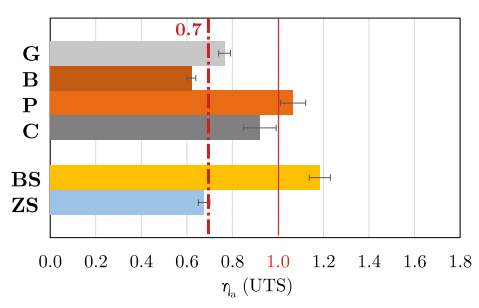

(a) Salt-water (SW)

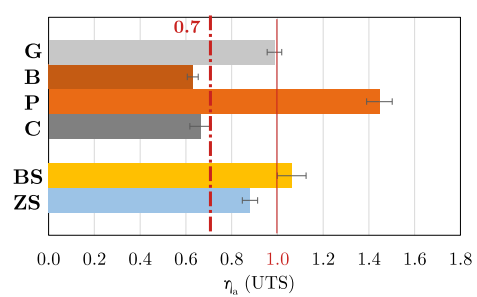

(c) Distilled water (DW)

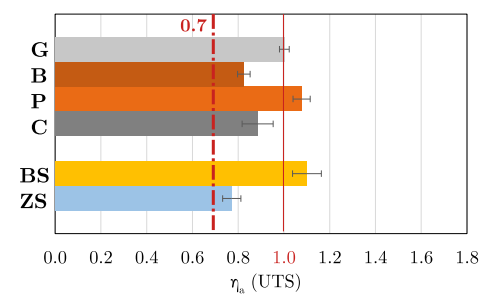

(b) Alkaline (AK)

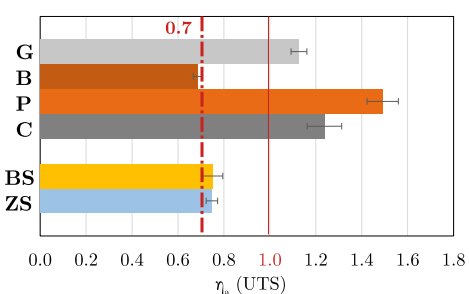

(d) Hydrochloric acid (HA)

Fig. 7 Mean environmental conversion factors for UTS, $\eta_{a}(f)$ for different reinforcing fabrics: G (glass, grey), B (basalt, amaranth), P (PBO, orange) and C (black, carbon), BS (ochre, brass-plated steel) and ZS (blue, zinc-plated steel). The acceptance limit is also shown (red, dash-dot)

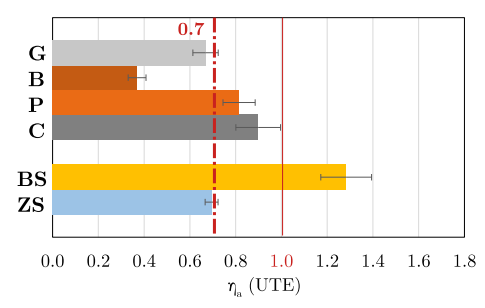

(a) Salt-water (SW)

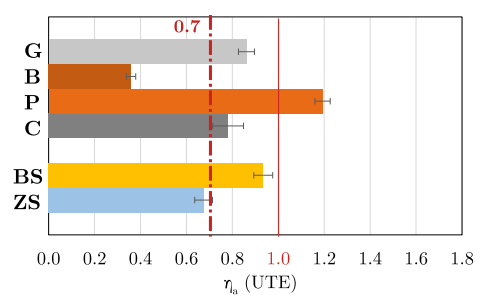

(c) Distilled water (DW)

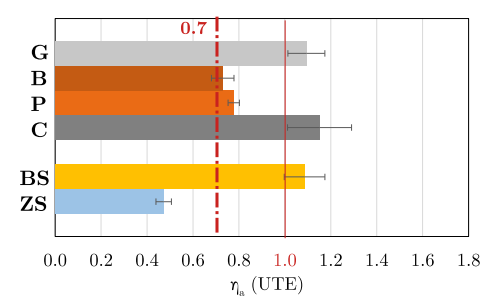

(b) Alkaline (AK)

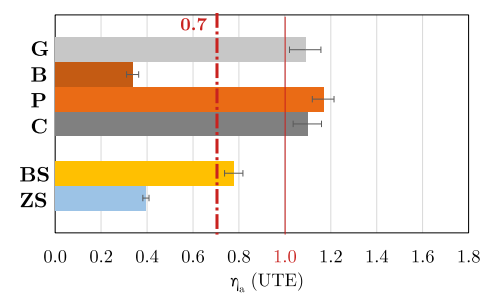

(d) Hydrochloric acid (HA)

Fig. 8 Mean environmental conversion factors for UTE, $\eta_{a}(\varepsilon)$ for different reinforcing fabrics: $\mathrm{G}$ (glass, grey), B (basalt, amaranth), $\mathrm{P}$ (PBO, orange) and $\mathrm{C}$ (black, carbon), BS (ochre, brass-plated steel) and ZS (blue, zinc-plated steel). The acceptance limit is also shown (red, dash-dot) 
where the ratio is computed for all possible choices of the numerator and of the denominator, respectively in the exposed and in the control group. This is method (b) described in [28]. Then, we may compute the sample mean $\mu\left(\eta_{a}\right)$, which is illustrated in Fig.7 and 8 for UTS and UTE, respectively. An analogous analysis is carried out for dissipated energy $W$, which relevant conversion factors are graphically reported as supplementary material. In general, the provision $\eta_{a}=70 \%$ works out surprisingly well as a lower design limit for strength and elongation, with the partial exception of basalt (B) and zinc-plated steel (ZS), which fare significantly below. Consideration of energy dissipation is more demanding and yet the $70 \%$ lower limit still stands, although now also carbon in DW and BS in HA score below. The following considerations may be put forward:

- B is generally worst performing in all environments in terms of UTS, UTE and dissipated energy $W$, with the exception of AK, where it scores better than ZS. In general, it substantially underperforms the $70 \%$ lower design limit.

- Conversely, PBO is generally best performing in every respect, for it shows little performance decay after exposure, if not improvement. In particular, it displays impressive performance gains in DW and HA.

- $\mathrm{G}$, similarly to $\mathrm{C}$, fares rather well in all environments in every respect: it might slightly underperform $70 \%$ UTE in SW, where C is preferable, yet it is the best choice in AK, even superior to P. Unexpectedly, C performs poorly in DW.

- BS performs exceedingly well in SW, and very well in AK and DW, while it scores rather poorly in HA.

- ZS is hardly a good option in any environment and underperforms the $70 \%$ lower design limit in terms of UTE in AK and HA.

In the previous analysis no consideration has been given to the uncertainty connected to the evaluation of the environmental conversion factor. To remediate this shortcoming, we consider a $95 \%$ confidence interval for the mean and assume it is normally distributed,

$$
\eta_{a_{d}}=\mu\left(\eta_{a}\right)-1.96 \frac{\mathrm{SD}\left(\eta_{a}\right)}{\sqrt{N_{p}}}
$$

where $N_{p}=N \hat{N}$ is the entity of the statistical population of the random variable $\eta_{a}$, as defined by Eq.(5). We thus obtain the material selection table of Fig.9.

\section{Conclusions}

Fig.9 ranks the reinforcing fabrics in terms of residual performance after exposure to different aggressive environments, with respect to the corresponding unexposed (control) specimen. It reports the environmental conversion factor lower limits in a $95 \%$ confidence interval, according to Eq.(6). As such, it provides a convenient first-glance material selection table for scientists and practitioners. From it, we see that

- the $70 \%$ lower limit performance advocated in the Italian guidelines [11] is generally sound but may be significantly breached downwards. In fact, this occurs 7 times for UTS and 11 for UTE out of 24 combinations, although mainly owing to basalt (B) and zinc-plated steel (ZS). 


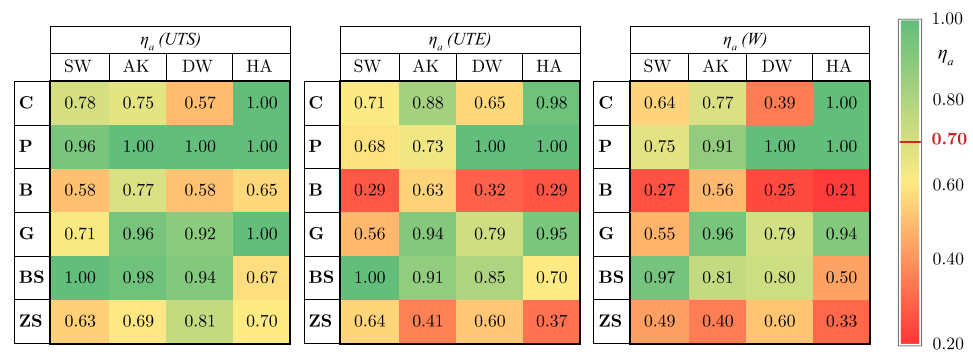

Fig. 9 Material selection table in terms of design environmental conversion factors, $\eta_{a_{d}}$, for UTS, UTE and $W$ within a $95 \%$ confidence interval

- brass-plated steel (BS) and PBO (P) are, almost always, the optimal choice, but the advantage over the second best, mainly AR-glass $(\mathrm{G})$, is not large. Noticeably poor performance is attained by $\mathrm{BS}$ in acid conditions and $\mathrm{P}$ in salt water;

- carbon (C) and glass (G) perform similarly, with a significant margin in favour of the latter. In fact, the former appears preferable only in marine conditions. Conversely, carbon exhibits a surprisingly poor performance in distilled water.

- zinc-plated (galvanized) steel (ZS) and basalt (B) are never really an option in light of their performance that often scores two or even three times less than the best candidate.

We conclude that careful selection of the reinforcing fabric plays a significant role in the determination of the durability of the composite. In this respect, the commonto-all-fabric environmental conversion factor given in the Italian guidelines conceals large performance differences, which should be capitalized at the design stage. Finally, best design options, in terms of durability, are available both in the SRG and in the TRC groups.

Acknowledgements The contribution of Elsa Litterio and Andrea Tamagnini in specimen manufacturing and curing is worth to be mentioned.

\section{Compliance with Ethical Standards}

Funding

This study was funded by "FAR2019 - Piano di Sviluppo Dipartimentale DIEF" (grant DR n.498/2019).

\section{Conflict of interest}

The authors declare that they have no conflict of interest.

\section{References}

1. Acceptance criteria for masonry and concrete strengthening using fiber-reinforced cementitious matrix (FRCM) composite systems. Guidelines, ICC-Evaluation Service, Whittier, CA, USA (2013) 
2. Guide to design and construction of externally bonded fabric-reinforced cementitious matrix (FRCM) systems for repair and strengthening concrete and masonry structures. Tech. rep., American Concrete Institute (ACI) (2013)

3. Alecci, V., Focacci, F., Rovero, L., Stipo, G., De Stefano, M.: Extrados strengthening of brick masonry arches with PBO-FRCM composites: Experimental and analytical investigations. Compos Struct 149, 184-196 (2016)

4. Arboleda, D.: Fabric reinforced cementitious matrix (FRCM) composites for infrastructure strengthening and rehabilitation: Characterization methods. Ph.D. thesis, University of Miami (2014). Open Access Dissertation. Paper 1282

5. Arboleda, D., Babaeidarabad, S., Hays, C., Nanni, A.: Durability of fabric reinforced cementitious matrix (FRCM) composites. In: Proceedings 7th international conference on FRP composites in civil engineering, CICE (2014)

6. Ascione, F., Lamberti, M., Napoli, A., Realfonzo, R.: SRP/SRG strips bonded to concrete substrate: Experimental characterization. Special Publication 326, 110-1 (2018)

7. Standard practice for the preparation of substitute ocean water. Standard, American Society for Testing and Materials (ASTM) (1998)

8. Standard practice for testing water resistance of coatings in $100 \%$ relative humidity. Standard, American Society for Testing and Materials (ASTM) (2002)

9. Brameshuber, W.: Report 36: Textile reinforced concrete-state-of-the-art report of RILEM TC 201-TRC, vol. 36. RILEM publications (2006)

10. Istruzioni per la progettazione, l'esecuzione ed il controllo di interventi di consolidamento statico mediante l'utilizzo di compositi fibrorinforzati. Italian standard for frp, National Research Council (2013)

11. Istruzioni per la progettazione, l'esecuzione ed il controllo di interventi di consolidamento statico mediante l'utilizzo di compositi fibrorinforzati a matrice inorganica. Italian standard for frcm, Italian National Research Council, Rome (2018)

12. Linea guida per la identificazione, la qualificazione ed il controllo di accettazione di compositi fibrorinforzati a matrice inorganica (FRCM) da utilizzarsi per il consolidamento strutturale di costruzioni esistenti. Italian standard for the qualification of frcm composite systems for externally bonded reinforcement of existing structures, Consiglio Superiore dei Lavori Pubblici (2019)

13. De Santis, S., Ceroni, F., de Felice, G., Fagone, M., Ghiassi, B., Kwiecień, A., Lignola, G.P., Morganti, M., Santandrea, M., Valluzzi, M.R., et al.: Round robin test on tensile and bond behaviour of steel reinforced grout systems. Compos Part B-Eng 127, 100-120 (2017)

14. De Santis, S., de Felice, G.: Steel reinforced grout systems for the strengthening of masonry structures. Compos Struct 134, 533-548 (2015)

15. De Santis, S., de Felice, G.: Tensile behaviour and durability of mortar-based strengthening systems with glass-aramid textiles. In: Key Eng Mat, vol. 624, pp. 346-353. Trans Tech Publ (2015)

16. Donnini, J.: Durability of glass FRCM systems: Effects of different environments on mechanical properties. Compos Part B-Eng p. 107047 (2019)

17. Eurocode -basis of structural design. Tech. rep., European Committee for Standardization (CEN) (2005)

18. Falope, F.O., Lanzoni, L., Tarantino, A.: Double lap shear test on steel fabric reinforced cementitious matrix (SFRCM). Compos Struct 201, 503-513 (2018)

19. Kajorncheappunngam, S., Gupta, R., GangaRao, H.: Effect of aging environment on degradation of glass-reinforced epoxy. J Compos Constr 6(1), 61-69 (2002)

20. Koutas, L.N., Tetta, Z., Bournas, D.A., Triantafillou, T.C.: Strengthening of concrete structures with textile reinforced mortars: State-of-the-art review. J Compos Constr 23(1), 03118001 (2019). DOI 10.1061/(ASCE)CC.1943-5614.0000882

21. Messori, M., Nobili, A., Signorini, C., Sola, A.: Mechanical performance of epoxy coated AR-glass fabric Textile Reinforced Mortar: Influence of coating thickness and formulation. Compos Part B-Eng 149, 135-143 (2018)

22. Messori, M., Nobili, A., Signorini, C., Sola, A.: Effect of high temperature exposure on epoxy-coated glass textile reinforced mortar (GTRM) composites. Constr Build Mater 212, 765-774 (2019)

23. Micelli, F., Aiello, M.A.: Residual tensile strength of dry and impregnated reinforcement fibres after exposure to alkaline environments. Compos Part B-Eng 159, 490-501 (2019)

24. Mobasher, B.: Mechanics of fiber and textile reinforced cement composites. CRC press (2011) 
25. Nanni, A.: A new tool for concrete and masonry repair. Concrete international 34(4), 43-49 (2012)

26. Nobili, A.: Durability assessment of impregnated glass fabric reinforced cementitious matrix (GFRCM) composites in the alkaline and saline environments. Constr Build Mater 105, 465-471 (2016)

27. Nobili, A., Falope, F.O.: Impregnated carbon fabric-reinforced cementitious matrix composite for rehabilitation of the Finale Emilia hospital roofs: case study. J Compos Constr 21(4), 05017001 (2017)

28. Nobili, A., Signorini, C.: On the effect of curing time and environmental exposure on impregnated carbon fabric reinforced cementitious matrix (CFRCM) composite with design considerations. Compos Part B-Eng 112, 300-313 (2017)

29. Purnell, P., Beddows, J.: Durability and simulated ageing of new matrix glass fibre reinforced concrete. Cement Concrete Comp 27(9-10), 875-884 (2005)

30. Purnell, P., Short, N., Page, C., Majumdar, A.: Microstructural observations in new matrix glass fibre reinforced cement. Cement Concrete Res 30(11), 1747-1753 (2000)

31. RILEM Technical Committee 232-TDT: Test methods and design of textile reinforced concrete. Mater Struct 49(12), 4923-4927 (2016)

32. Signorini, C., Nobili, A., Falope, F.O.: Mechanical performance and crack pattern analysis of aged carbon fabric cementitious matrix (CFRCM) composites. Compos Struct 202, 1114 - 1120 (2018). Special issue dedicated to Ian Marshall

33. Signorini, C., Nobili, A., Siligardi, C.: Sustainable mineral coating of alkali-resistant glass fibres in textile-reinforced mortar composites for structural purposes. J Compos Mater 53(28-30), 4203-4213 (2019). DOI 10.1177/0021998319855765. URL https://doi.org/10.1177/0021998319855765

34. Signorini, C., Sola, A., Nobili, A., Siligardi, C.: Lime-cement textile reinforced mortar (TRM) with modified interphase. J Appl Biomater Funct 17(1) (2019). DOI $10.1177 / 2280800019827823$

35. Tekieli, M., De Santis, S., de Felice, G., Kwiecień, A., Roscini, F.: Application of digital image correlation to composite reinforcements testing. Compos Struct 160, 670-688 (2017)

36. Methods of test for mortar for masonry - part 11: Determination of flexural and compressive strength of hardened mortar. Standard, Ente nazionale italiano di unificazione (2007) 